\title{
Methods and Techniques Used to Convey Total System Performance Assessment Analyses and Results for Site Recommendation at Yucca Mountain, Nevada, USA
}

Patrick D. Mattie

Jerry A. McNeish

S. David Sevougian

Duke Engineering and Services, Inc.

1180 Town Center Drive

Las Vegas, NV 89144

USA

Email: Mcneish@notes.ymp.gov

\author{
Robert W. Andrews \\ Bechtel SAIC Company, LLC \\ 1180 Town Center Drive \\ Las Vegas, NV 89144 \\ USA
}

\begin{abstract}
Cog

Total System Performance Assessment (TSPA) is used as a key decision-making tool for the potential geologic repository (of high level radioactive waste at Yucca Mountain, Nevada, USA. Because of the complexity and uncertainty involved in a post-closure performance assessment, an important goal is to produce a transparent document describing the assumptions, the intermediate steps, the results, and the conclusions of the analyses. An important objective for a TSPA analysis is to illustrate confidence in performance projections of the potential repository given a complex system of interconnected process models, data, and abstractions. The methods and techniques used for the recent TSPA analyses demonstrate an effective process to portray complex models and results with transparency and credibility.
\end{abstract}

\section{Introduction}

The U.S. Department of Energy (DOE) has been evaluating the feasibility of disposing high level radioactive waste at a potential repository at Yucca Mountain, Nevada. The wastes consistsof spent fuel from commercial nuclear reactors around the U.S. as well as defense and other high level wastefin the form of vitrified glass or spent fuel stored at DOE facilities. An important milestone in the decision making process is the determination of the suitability of the Yucca Mountain site as a long-term repository for the wastese The DOE has been conducting numerous scientific and engineering investigations for the last 20 years to evaluate the suitability of the site.

An important element in the determination of site suitability is the evaluation of the performance of the site and the associated engineered barriers following repository closure. This evaluation includes an assessment of the likely ability of the waste disposal concept to meet the applicable radiation protection standards. The method 
and criteria for evaluating post-closure suitability were proposed by the DOE in 10 CFR part 963 (64 FR 67054)[1]. An element of the requirements for the suitability evaluation is the completion of a total system performance assessment and a comparison of the projected performance with the applicable standards to assess compliance.

A total system performance assessment (TSPA) for the Yucca Mountain repository system has recently been completed. This TSPA has been documented by the Civilian Radioactive Waste Management System Management and Operating (CRWMS M\&O) contractor in a technical report entitled Total System Performance Assessment for the Site Recommendation [2]. The purpose of this paper is to present the TSPA approach and example results to demonstrate their effectiveness in portraying complex models and results with transparency and credibility.

\section{The Approach}

The objective of the TSPA is to provide a clear and understandable assessment of repository performance at the potential Yucca Mountain Site as part of the site recommendation process. To achieve this objective, the TSPA document includes:

- An assimilation of all the available scientific data and analyses that describe the geological setting into which the design concept is to be placed

- Definition of the design concept that is to be used

- Description of the behavior of the potential repository system in a traceable, transparent manner

- Identification of the standards by which the performance of the repository is estimated using TSPA.

The total repository system is comprised of both geological and engineering components. Thus, the TSPA uses the available scientific information about naturally occurring physical and chemical processes at the Yucca Mountain site. In addition, the TSPA includes the design concepts and detailed scientific information about physical and chemical processes involving the engineered components. Conveying the implementation of complex TSPA components and results requires an integrated approach combining detailed text and graphics that facilitate a transparent and clear understanding of the processes and results.

Building an integrated TSPA model requires input from the many disciplines that compose the system. In particular, the recent TSPA analyses are based on a sequence of modelling activities that start with the development of process level models, which are intended to capture the key aspects of the natural and engineered systems. In turn many of these process level models are simplified further into what are termed abstraction models. The TSPA integrated model for Yucca Mountain is hence, comprised of a detailed interconnection of both process level models and abstractions. 
Explaining the completely integrated TSPA model and establishing that the TSPA analyses have adequately modeled the behavior of the engineered and natural systems at Yucca Mountain is a difficult task. To build confidence and transparency into the TSPA analyses, the documentation must illustrate with sufficient clarity the following confidence building attributes (e.g. demonstrate that the TSPA has sufficiently defined the expected future performance of the potential repository):

- The conceptual basis for the individual components in the quantitative analyses (i.e., how the system is intended to work)

- The processes used to combine the individual components into an assessment of system behavior

- The scientific understanding used to develop the quantitative analysis tools that describe the system's expected evolution

- The system's expected evolution as defined by the spatial and temporal response of the system to the waste emplacement

- The uncertainty in the system's expected evolution and the significance of that uncertainty to the system-performance goals.

The construction of the model also benefits from comments from internal and external reviewers of previous system analyses conducted for the potential repository. When documenting each of the confidence building attributes, the consistent use of graphical icons and diagrams aids in creating a transparent description of information flow throughout the TSPA. A transparent description helps to impart a high level of understanding to the stakeholders, many of whom may not be technically sophisticated in the nuances involved in a TSPA approach.

The general TSPA method is illustrated in Figure 1. Starting with a basic design concept, information is collected by project scientists regarding the environment that is germane to the proposed site and associated engineered barriers. This information is used to develop models of the relevant processes, first at the conceptual level and then at the detailed or process level (e.g. Mathematical and/or Numerical Models) and finally at a simplified or abstracted level suitable for inclusion in the probabilistic TSPA model. Throughout this process the uncertainty in the various parameters is either quantified or appropriately bounded in cases of high complexity. The role of the performance assessment is then to integrate these processes and to evaluate the significance of the uncertainty with respect to the ability of the system to meet the regulatory objectives.

\section{The TSPA Model}

The components included in the TSPA model for the Yucca Mountain repository system are schematically illustrated in Figure 2 . This figure illustrates the relevant attributes of the repository system, as follows: 


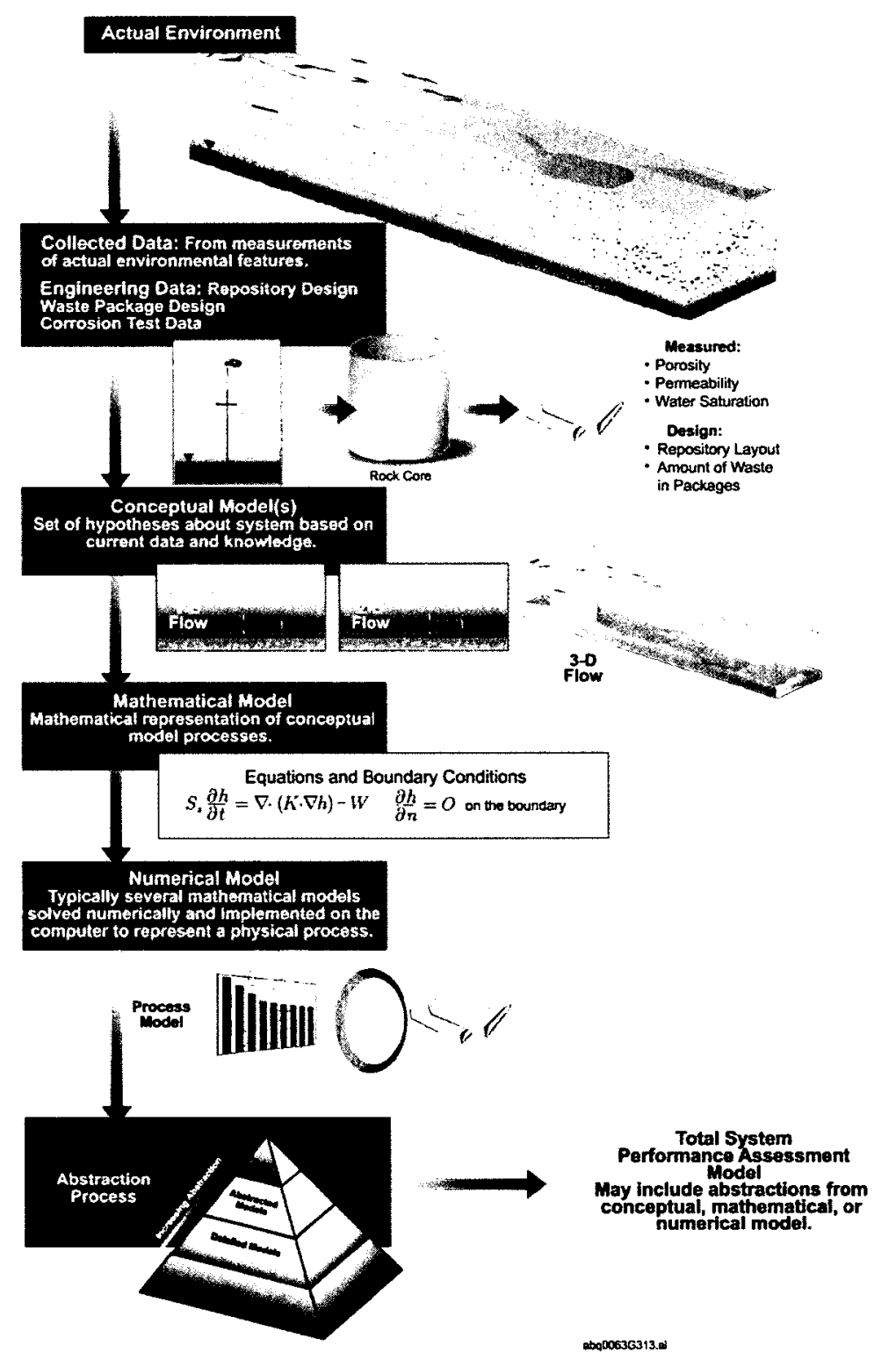

Figure 1. General Approach in the Development of a Total System.

- Limiting the amount of water contacting waste package - this includes processes that affect water movement above the repository horizon (such as the climate, net infiltration, and unsaturated zone hydrology) and the possible ingress of water into the emplacement drifts through seepage.

- Prolonging waste package lifetime - this includes processes that affect the degradation rate of the engineered barriers, including the 


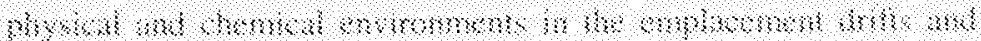

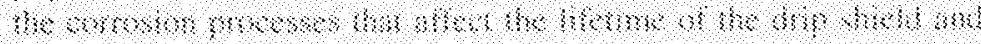

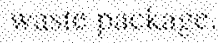

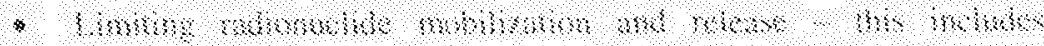

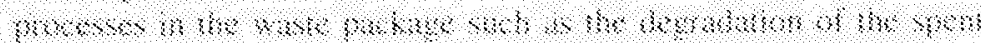

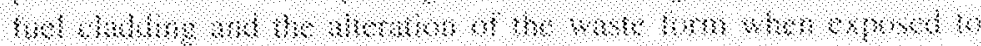

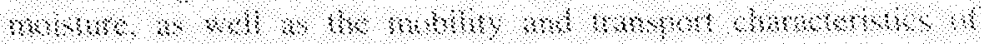

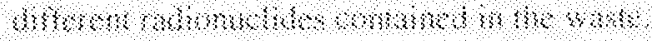

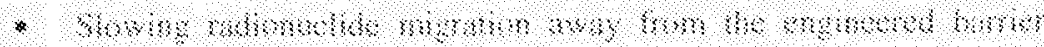

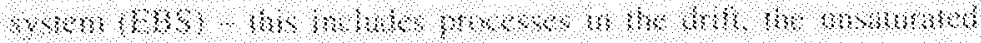

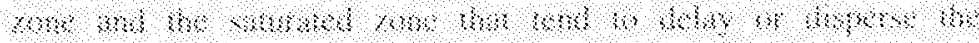

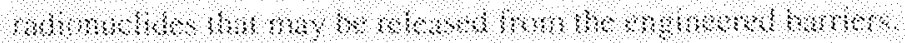

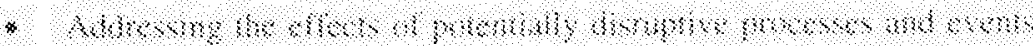

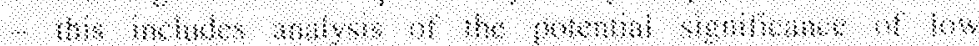

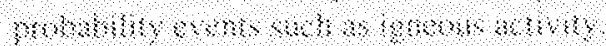

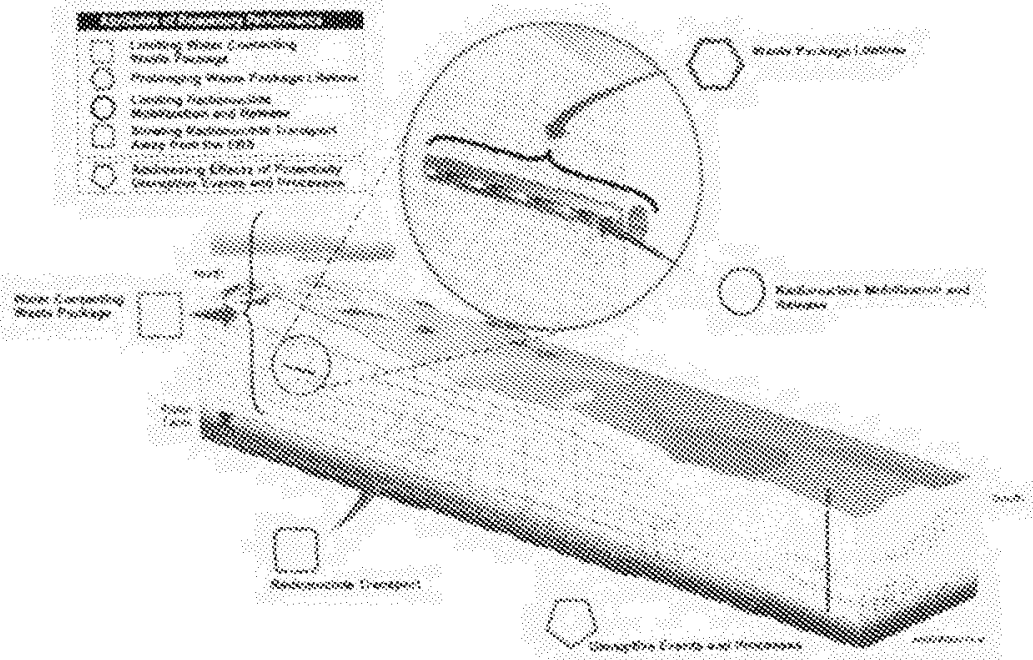

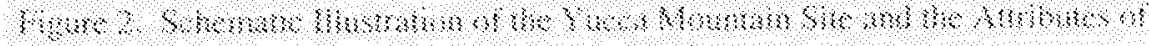

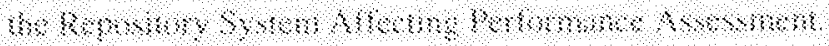

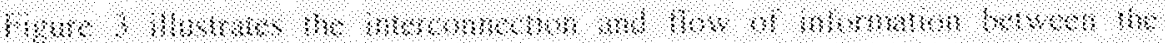

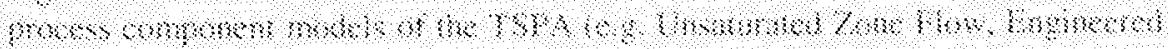

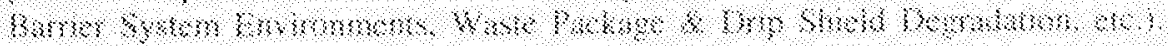

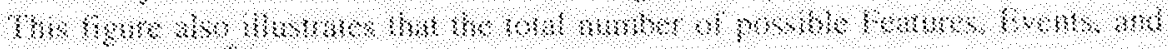

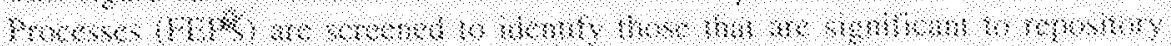

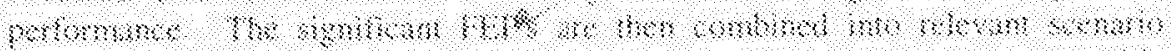

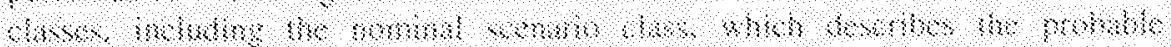

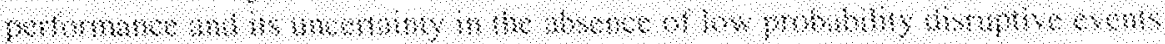

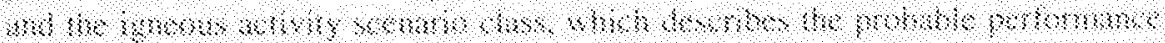

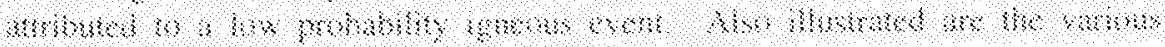




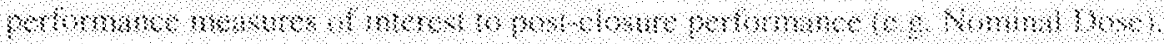

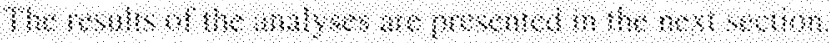

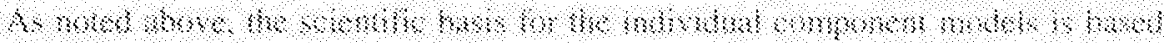

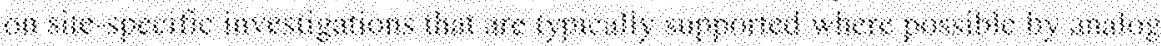

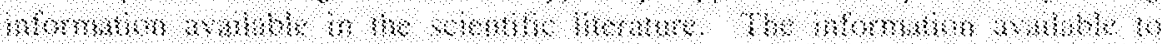

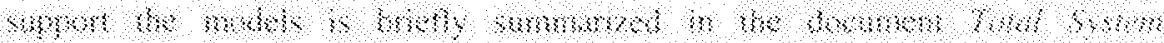

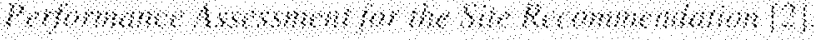

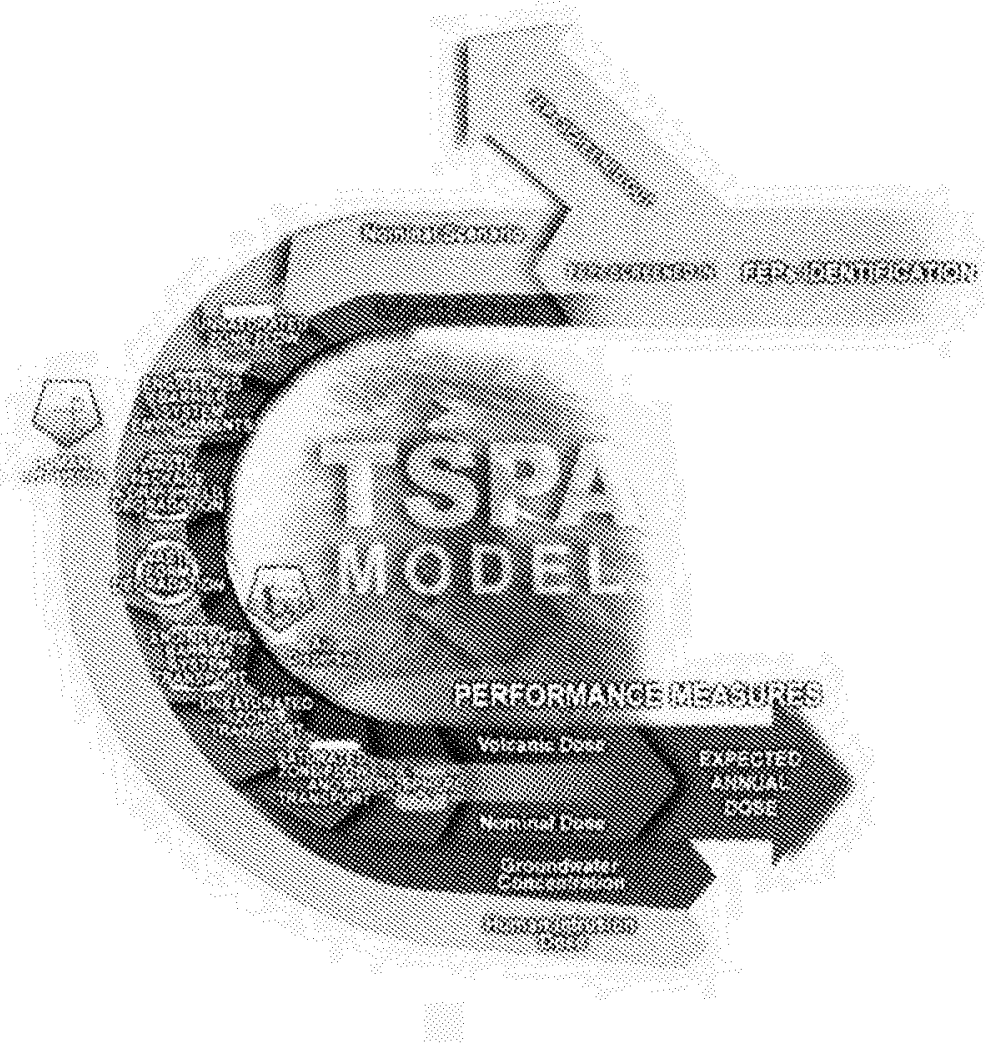

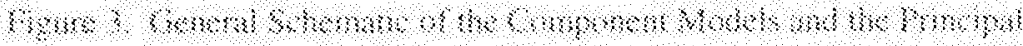

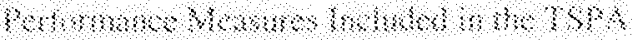

\section{Kxample Reswhls}

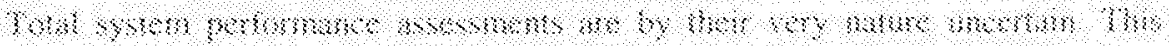

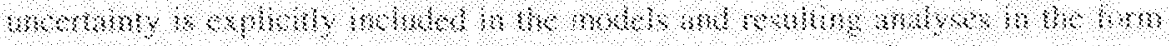

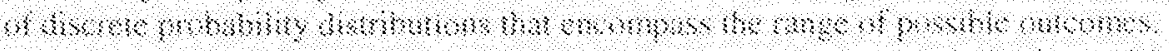

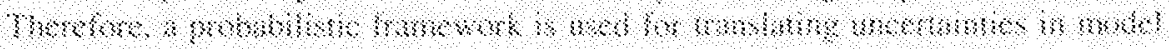

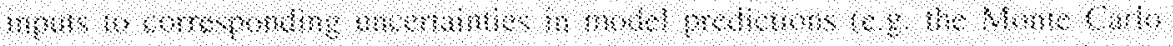

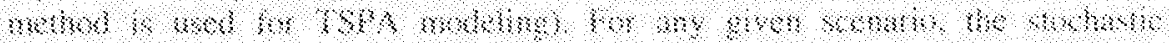

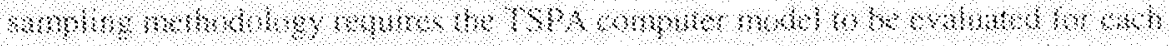

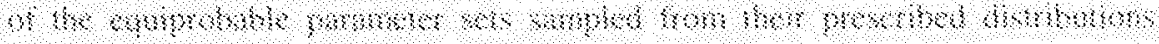




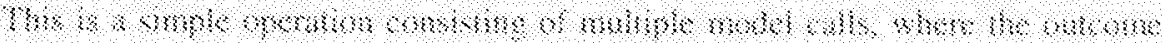

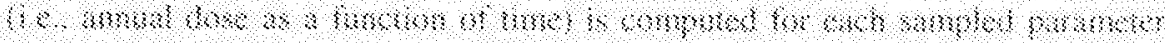

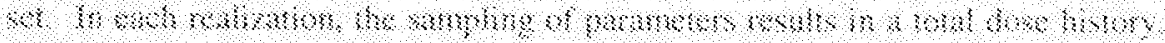

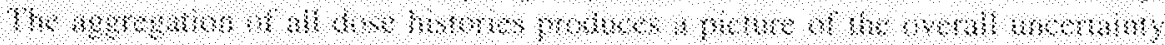

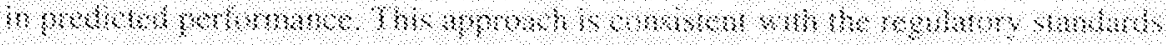

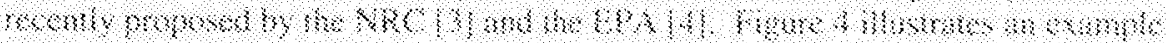

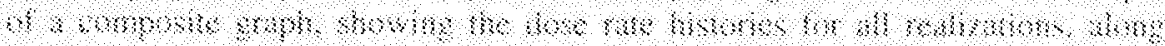

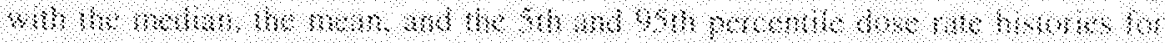

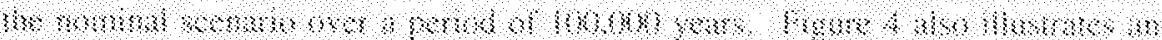

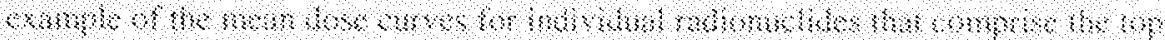

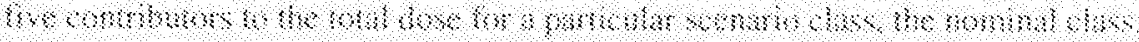

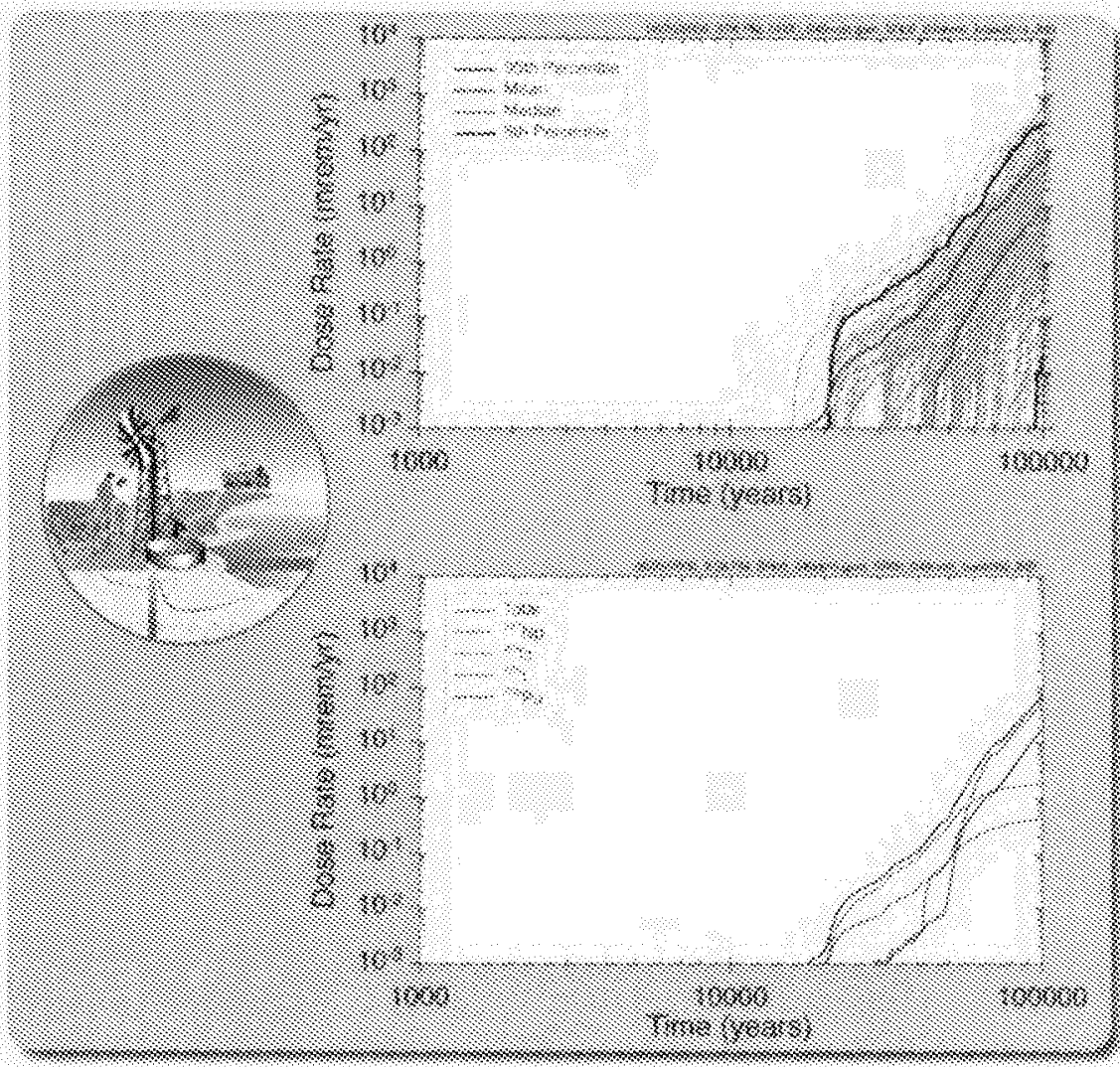

↔,

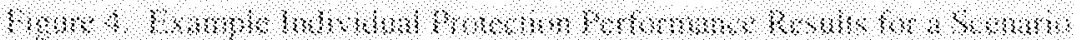

औ,

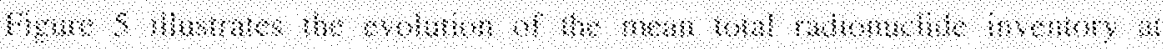

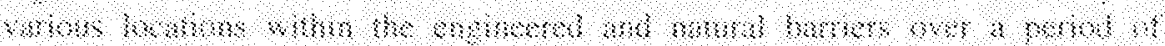

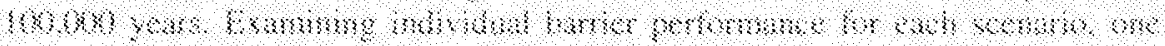

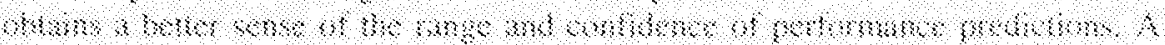

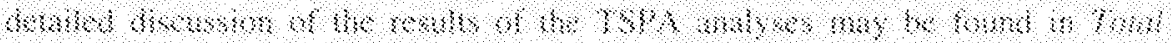

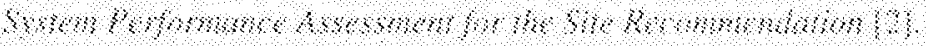




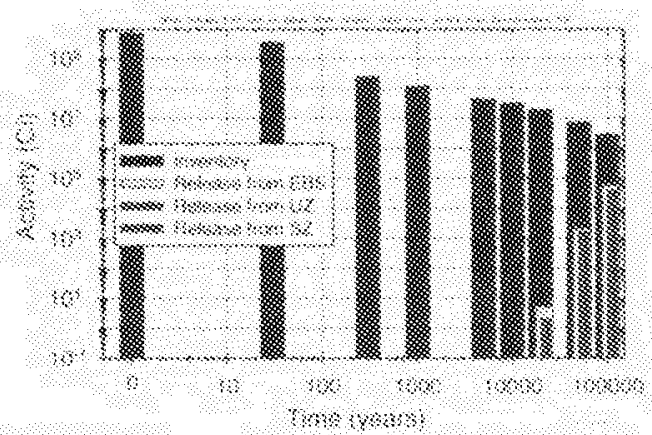

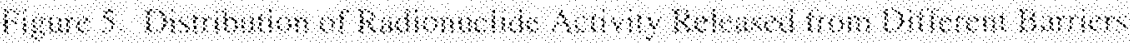

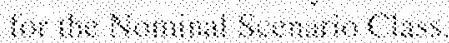

\section{Sพmmmหxry}

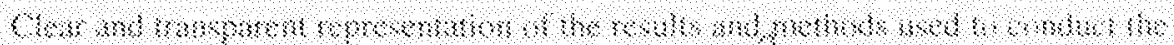

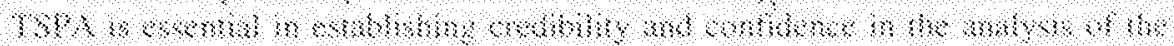

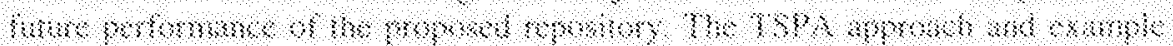

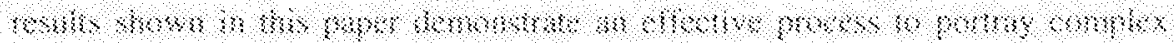

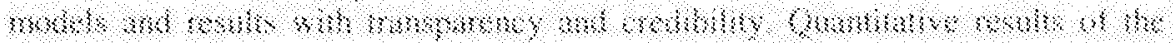

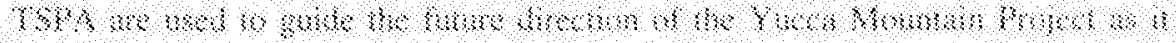

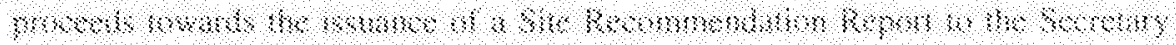

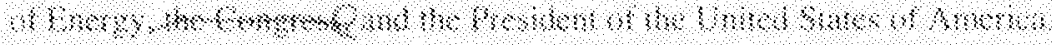

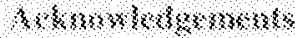

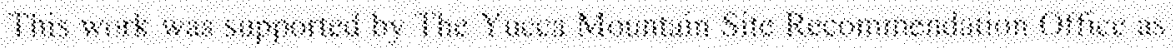

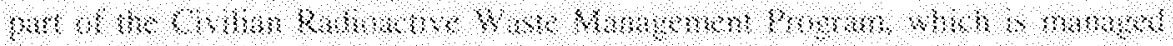

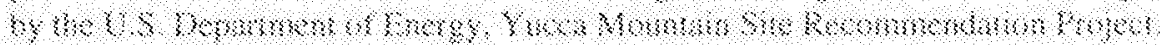

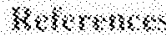

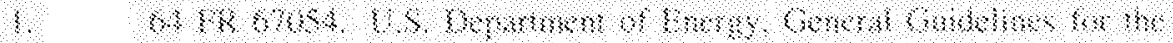

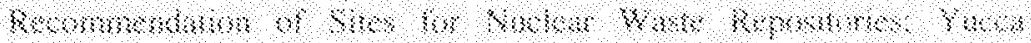

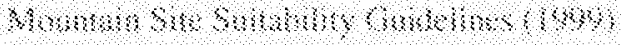

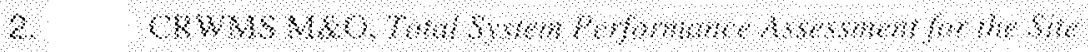

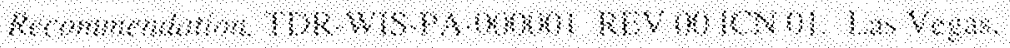

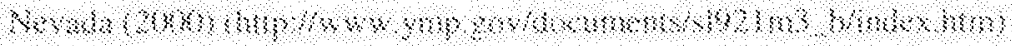

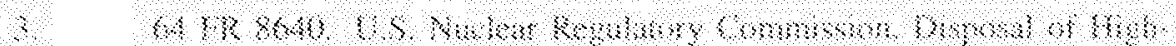

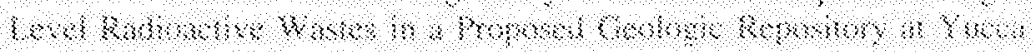

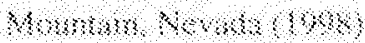

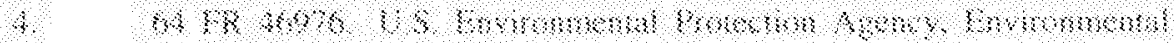

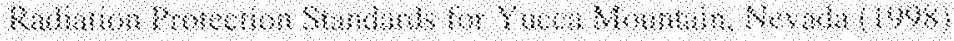

